\title{
Brain Activity during Methamphetamine Anticipation in a Non-Invasive Self-Administration Paradigm in Mice
}

\author{
[DClaudia Juárez-Portilla, ${ }^{1,2}$ Michael Pitter, ${ }^{3}{ }^{1}$ Rachel D. Kim, ${ }^{1}$ Pooja Y. Patel, ${ }^{1}$ Robert A. Ledesma, ${ }^{3}$ \\ (D) Joseph LeSauter, ${ }^{1,3}$ and ${ }^{-}$Rae Silver ${ }^{1,3,4}$
}

\section{DOI:http://dx.doi.org/10.1523/ENEURO.0433-17.2018}

${ }^{1}$ Department of Psychology, Barnard College, New York, NY 10027, ${ }^{2}$ Centro de Investigaciones Biomédicas, Universidad Veracruzana, Xalapa, Veracruz 91190, México, ${ }^{3}$ Department of Psychology, Columbia University, New York, NY 10027, and ${ }^{4}$ Department of Pathology and Cell Biology, Columbia University Health Sciences, New York, NY 10027

\section{Visual Abstract}

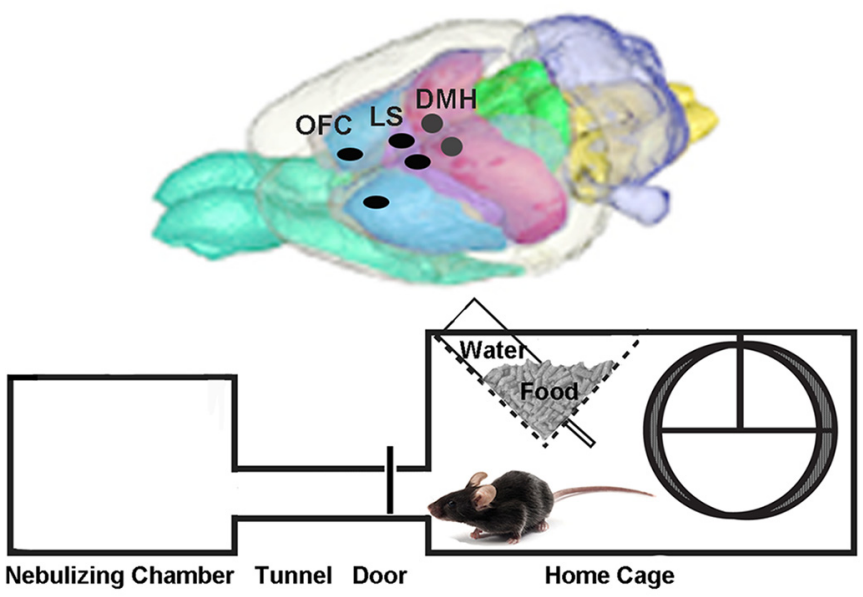

Animals live in the home cage that is connected to the nebulizing chamber by a tunnel. The orbitofrontal cortex (OFC), lateral septum (LS) and dorsomedial hypothalamus $(\mathrm{DMH})$ are activated in anticipation of access to the nebulizing chamber when methamphetamine, but not water, is available.
The ability to sense time and anticipate events is critical for survival. Learned responses that allow anticipation of the availability of food or water have been intensively studied. While anticipatory behaviors also occur prior to availability of regularly available rewards, there has been relatively little work on anticipation of drugs of abuse, specifically methamphetamine (MA). In the present study, we used a protocol that avoided possible CNS effects of stresses of handling or surgery by testing anticipation of MA availability in animals living in their home cages, with daily voluntary access to the drug at a fixed time of day. Anticipation was operationalized as the amount of wheel running prior to MA availability. Mice were divided into four groups given access to either nebulized MA or water, in early or late day. Animals with access to MA, but not water controls, showed anticipatory activity, with more anticipation in early compared to late day and significant interaction effects. Next, we explored the neural basis of the MA anticipation, using c-FOS expression, in animals eutha-

\section{Significance Statement}

A primary function of the brain is to predict future events. Brain regions regulating anticipation of drugs have received little analysis. We studied methamphetamine (MA) anticipation in mice living in their home cage and having access to nebulized MA for $1 \mathrm{~h}$ daily via a tunnel to a nebulizing chamber. Mice spontaneously awakened from sleep $\sim 2 \mathrm{~h}$ before MA availability and voluntarily entered the chamber when accessible. This protocol avoided the potential CNS effects associated with handling, injections and surgery. c-FOS expression before MA availability was observed in the dorsomedial hypothalamus (DMH), lateral septum (LS), and orbitofrontal cortex (OFC), suggesting that anticipation of regularly scheduled MA is associated with activation of brain regions important in circadian timing, emotional regulation, and decision making. 
nized at the usual time of nebulization access. In the dorsomedial hypothalamus (DMH) and orbitofrontal cortex (OFC), the pattern of c-FOS expression paralleled that of anticipatory behavior, with significant main and interaction effects of treatment and time of day. The results for the lateral septum (LS) were significant for main effects and marginally significant for interaction effects. These studies suggest that anticipation of MA is associated with activation of brain regions important in circadian timing, emotional regulation, and decision making.

Key words: anticipation; circadian; dorsomedial hypothalamus; lateral septum; nebulization; orbitofrontal cortex

\section{Introduction}

Abuse of methamphetamine (MA) is an international public health problem with an estimated 15-16 million users worldwide, making MA the second most widely abused drug after cannabis (United-Nations, 2011). Abuse of a psychostimulant such as MA has adverse and widespread consequences for the central nervous system (Richards and Laurin, 2018). While consequences of MA intake administered in the drinking water (Tataroglu et al., 2006; Honma and Honma, 2009) have been amply examined, the neural responses associated with the anticipation of MA availability are less well understood. Anticipation and prediction are fundamental functions of the brain; signals that a reward is imminent are associated with not only MA and other drugs, but also with rewards such as alcohol, food, highly palatable rewards and sweets, and sex (Pitchers et al., 2013; Webb et al., 2015). Such signals include distinctive external visual, auditory, or olfactory cues, and interoceptive responses. For example, before regularly scheduled meals, the CNS and peripheral organs produce signals that anticipate the availability of nutrients, thereby preparing the body for food intake [mouse (LeSauter et al., 2009), rat (Patton et al., 2014), and human (Ott et al., 2011, 2012); Patton and Mistlberger, 2013; Challet, 2015). While MA anticipation has not been directly tested in humans, there is evidence of contextual preference for stimuli paired with MA administration (Childs and de Wit, 2009; 2013; Mayo et al., 2013).

The circadian timing system is an important component of anticipation of daily recurring future events (Mellers et al., 1999). Circadian timing occurs in the

Received December 11, 2017; accepted February 21, 2018; First published March 12, 2018.

The authors declare no competing financial interests.

Author contributions: J.L. and R.S. designed research; C.J.-P. and M.P. performed research. C.J.-P., M.P., R.D.K., P.Y.P., R.A.L., and J.L. analyzed data; J.L. and R.S. wrote the paper.

This work was supported by the Consejo Nacional de Ciencia y Tecnología (CONACYT) Postdoctoral Fellowship Award 186902 and CONACYT Travel Grants 1010/152/2014 and C-133/2014 (to C.J.-P.), the Columbia University Summer Undergraduate Research Fellowship (R.D.K.), the Barnard College Summer Research Internship (R.D.K.), and funds from Barnard College and Columbia University (R.S.).

Correspondence should be addressed to Rae Silver, Department of Psychology, Mail Code 5501, Columbia University, 1190 Amsterdam Avenue, New York, NY 10027, E-mail: qr@columbia.edu.

DOI:http://dx.doi.org/10.1523/ENEURO.0433-17.2018

Copyright @ 2018 Juárez-Portilla et al.

This is an open-access article distributed under the terms of the Creative Commons Attribution 4.0 International license, which permits unrestricted use, distribution and reproduction in any medium provided that the original work is properly attributed. absence of all external timing signals, and is a function of the brain's master clock in the suprachiasmatic nucleus. Numerous studies demonstrate that when food or a palatable treat reward are offered to ad libitum fed rats during their sleep time, animals will anticipate by awakening hours before the appearance of the food (Mistlberger, 1994; Escobar et al., 2011). This phenomenon is also seen in nature (Caba and González-Mariscal, 2009) and in response to rewards other than food (Webb et al., 2009), and can occur to multiple regularly timed events each day (Stephan, 1983; Mistlberger et al., 2012). Though there are many parallels between food and drug reward systems (Alonso-Alonso et al., 2015; Tomasi et al., 2015), anticipatory interoceptive cues have been little studied in the context of time-of-day effects on drug intake (Siegel and Ramos, 2002; Siegel, 2005). That said, there is evidence that activation of pleasant interoceptive signals is a component of addictive behaviors (Stewart et al., 2015).

There are circadian effects on behaviors associated with anticipation of regularly scheduled drug injections. Following daily injections of MA, there is a gradual elevation, during the animal's normal sleep time, of locomotor activity in the time preceding the injection (Shibata et al., 1994). However, anticipatory activity does not appear in the absence of a circadian injection schedule (lijima et al., 2002), indicating that entrainment of the circadian timing system is required for the anticipation to develop. More evidence of a circadian component to anticipation is available in changes in c-FOS expression in anticipation of a daily meal, with studies in rats (Challet et al., 1997; Angeles-Castellanos et al., 2004, 2007; Mendoza et al., 2005; Escobar et al., 2007; Poulin and Timofeeva, 2008; Acosta-Galvan et al., 2011; Mitra et al., 2011; Caba et al., 2014), mice (Begriche et al., 2012; Blum et al., 2012; Gallardo et al., 2014; Dattolo et al., 2016; Luna-lllades et al., 2017), and hamsters (Dantas-Ferreira et al., 2015; Ruby et al., 2017), or in anticipation of a palatable treat in rats or mice (Mendoza et al., 2005; Mitra et al., 2011; Gallardo et al., 2012; Blancas et al., 2014).

For studies of drugs of abuse, the gold standard entails self-administration. Here we are interested in anticipatory responses associated with voluntary intake of MA. We use a non-invasive protocol that eliminates possible CNS effects of stress associated with handling, injections or surgery that may alter the anticipatory response to the drug. In this protocol, mice live in their home cage and have regularly scheduled daily access to nebulized MA or water for $1 \mathrm{~h}$ via a tunnel that leads to a chamber where the drug is nebulized and available during their normal sleep 
time (Juarez-Portilla et al., 2017). Here, we used this protocol to examine behavioral anticipation of MA availability and to identify c-FOS expression at the time of anticipation, before the availability of the drug.

The efficacy of the nebulized MA in this protocol has been previously demonstrated in several responses (JuarezPortilla et al., 2017). Mice spend average of $\sim 3 \mathrm{~min}$ in the chamber during the interval of MA availability. Elevated locomotor activity occurs during the $1 \mathrm{~h}$ of MA availability and for the $3 \mathrm{~h}$ thereafter. On the other hand, control mice with access to nebulized water have consistently low activity levels (Juarez-Portilla et al., 2017; Fig. 4). Importantly, following 3-min experimenter-imposed exposure to nebulized MA, serum levels are elevated in mice euthanized 20,60 , or 120 min later. Finally, the amount of time mice spend in the nebulizing chamber is inversely proportional to the concentration of nebulized MA indicating that they self-regulate their intake of MA (Juarez-Portilla et al., 2017; Fig. 5B).

\section{Materials and Methods}

\section{Animals and housing}

Male mice (strain C57BL/6N) were purchased from Jackson Laboratory at five to six weeks of age. The animals were group-housed ( 4 per cage, $28 \times 17 \times 12$ $\mathrm{cm})$ for $10 \mathrm{~d}$ on arrival and subsequently were housed individually in cages $(32 \times 14 \times 13 \mathrm{~cm})$ made of clear polycarbonate, provided with pine shavings and a running wheel $(11 \mathrm{~cm}$ in diameter). The wheel had a magnetic sensor connected to a computer enabling continuous monitoring of wheel revolutions. Standard mouse chow (Lab-Diet 5001; PMI Nutrition) and water were provided ad libitum, and room temperature was maintained at $21 \pm$ $1^{\circ} \mathrm{C}$. A dim red light ( $<1$ lux) was on at all times, allowing for animal handling and maintenance. Mice were housed for $17 \mathrm{~d}$ in a 12/12 h light/dark (LD) cycle, with lights on defined as zeitgeber time 0 (ZT0) and lights off as ZT12. Entrainment was confirmed for all animals. On experimental days, a skeleton photoperiod that allowed for continued entrainment was used, with lights on for $30 \mathrm{~min}$ at the beginning and end of the animal's day. In skeleton photoperiods, animals continue their behavior as though it were a full photoperiod, with their inactive phase (subjective day) at the prior time of lights on, and their active phase (subjective night) at the prior time of lights off (Patton et al., 2013; Rosenwasser et al., 2015). This lighting regimen provides the advantage of avoiding "masking"; i.e., the direct suppressive effects of light on activity that occurs in nocturnal species (Pittendrigh and Minis, 1964; Pittendrigh, 1981; Mrosovsky and Hattar, 2003). All experimental procedures were approved and conducted according to the Author's University Institutional Animal Care and Use Committee.

\section{Test apparatus and protocol}

The test apparatus, consisted of a tunnel $(7.1 \times 3.1 \times$ $3.1 \mathrm{~cm})$ connecting the home cage to a nebulization chamber $(11.4 \times 11.4 \times 6 \mathrm{~cm})$, as previously described (Juarez-Portilla et al., 2017). For delivery of vaporized material, a nebulizer (catalog \#40-370-000; Briggs Medi-

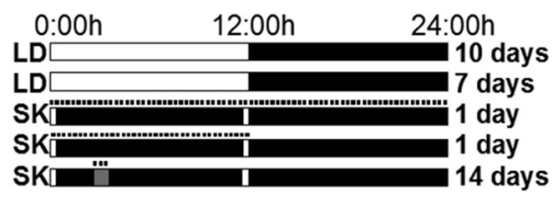

Figure 1. Schematic depicting experimental design. Mice were group-caged for $10 \mathrm{~d}$ and then housed singly for $7 \mathrm{~d}$. The LD cycle (white bar = lights on, black bar = lights off) was used for the first $17 d$ to establish entrainment. For the remainder of the study, a skeleton photoperiod was used (lights on ZTO-ZTO:30 and ZT11:30-ZT12:00) to maintain entrainment. MA or W was nebulized in the chamber at either ZT4 (gray bar) or ZT10 (not shown in cartoon). Dashes, tunnel door from home cage to nebulizing chamber is open; SK, skeleton photoperiod.

cal Service Company) was attached to the nebulization chamber through a polycarbonate tube. To familiarize the animals with the apparatus, the tunnel door was left open so mice could explore the tunnel and nebulizing chamber for $36 \mathrm{~h}$ starting on day 18 . Access to the tunnel was terminated the evening before the start of the study. On the 14 experimental days, the door to the tunnel was opened for $1 \mathrm{~h}$ daily, either $4 \mathrm{~h}$ (ZT4) or $10 \mathrm{~h}$ (ZT10) after lights on, allowing voluntary access to the nebulization chamber. Animals were perfused on experimental day 15 at ZT4 or ZT10. A cartoon depicting the experimental design is shown in Figure 1.

\section{Drug preparation}

MA hydrochloride (catalog \#M8750-5G, Sigma-Aldrich Corp) was dissolved in water at a concentration of 1 $\mathrm{mg} / \mathrm{ml}$ and nebulized for experimental animals. For control animals, water was nebulized. A volume of $7.5 \mathrm{ml}$ of nebulized MA or water was expressed from the nebulizer into the chamber during the 1-h interval of availability each day.

\section{Experimental groups}

Animals were divided into four groups ( $N=6 /$ group), as follows: water (W) or MA was nebulized in the chamber at either ZT4-ZT5 or at ZT10-ZT11 (group names, MA-ZT4, W-ZT4, MA-ZT10, and W-ZT10). One animal from the MA-ZT4 group failed to entrain to the skeleton photoperiod and was removed from the study.

\section{Behavioral measures and analysis}

Locomotor activity was quantified by monitoring wheel revolutions in 10-min bins throughout the 24-h day, using Vitalview Software (RRID:SCR_014497, Minimitter Inc.). Actograms were plotted using Clock Lab (RRID: SCR_014309, Actimetrics). To establish group means, data from each animal were normalized using standard methods (Landry et al., 2007; Butler and Silver, 2011; Gallardo et al., 2014). Thus, the amount of locomotor activity during the anticipatory interval, before MA availability, was assessed as a fraction of the individual's total locomotor activity (Figs. 2C, 3A ). The number of wheel revolutions per $10-\mathrm{min}$ bin divided by the average daily rotations and multiplied by 144 (the number of 10-min bins/d). For analysis of anticipatory behavior, wheel 
A

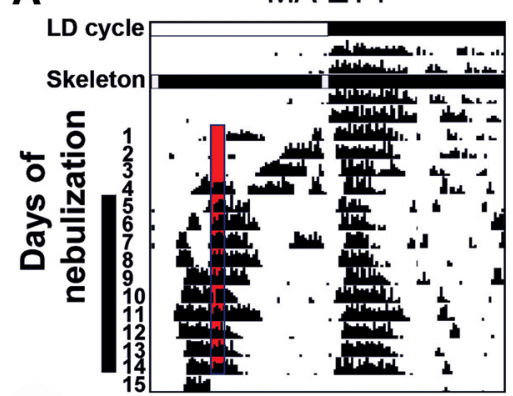

B

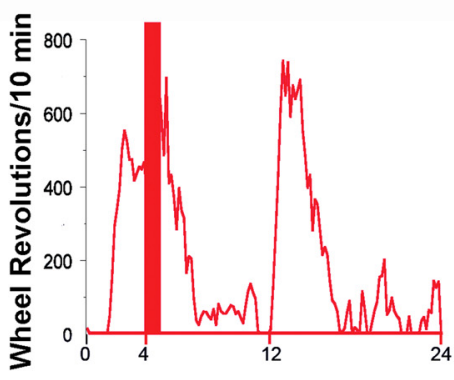

Locomotor Activity
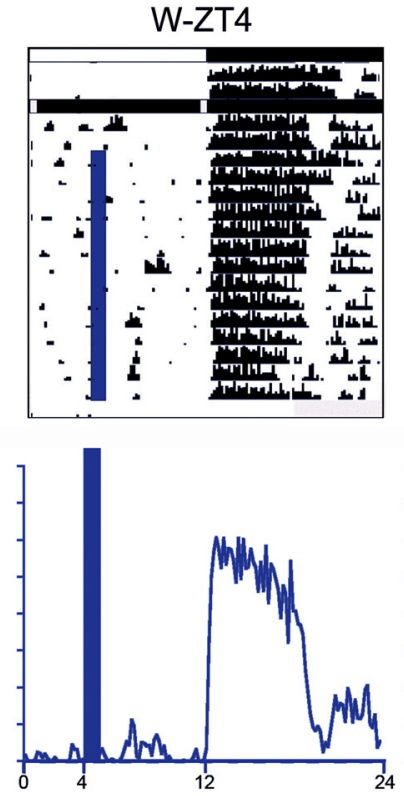
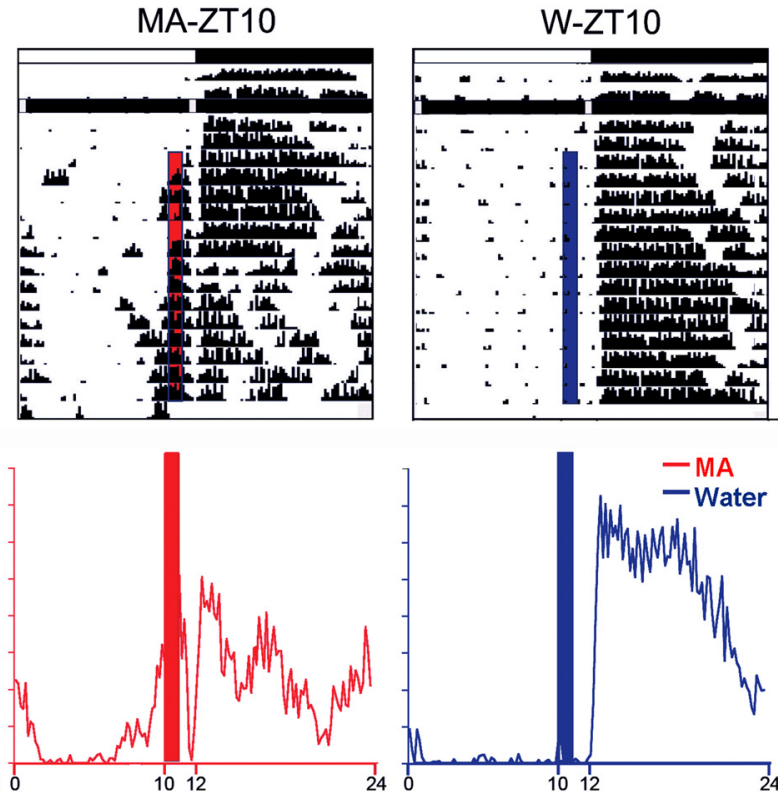

C
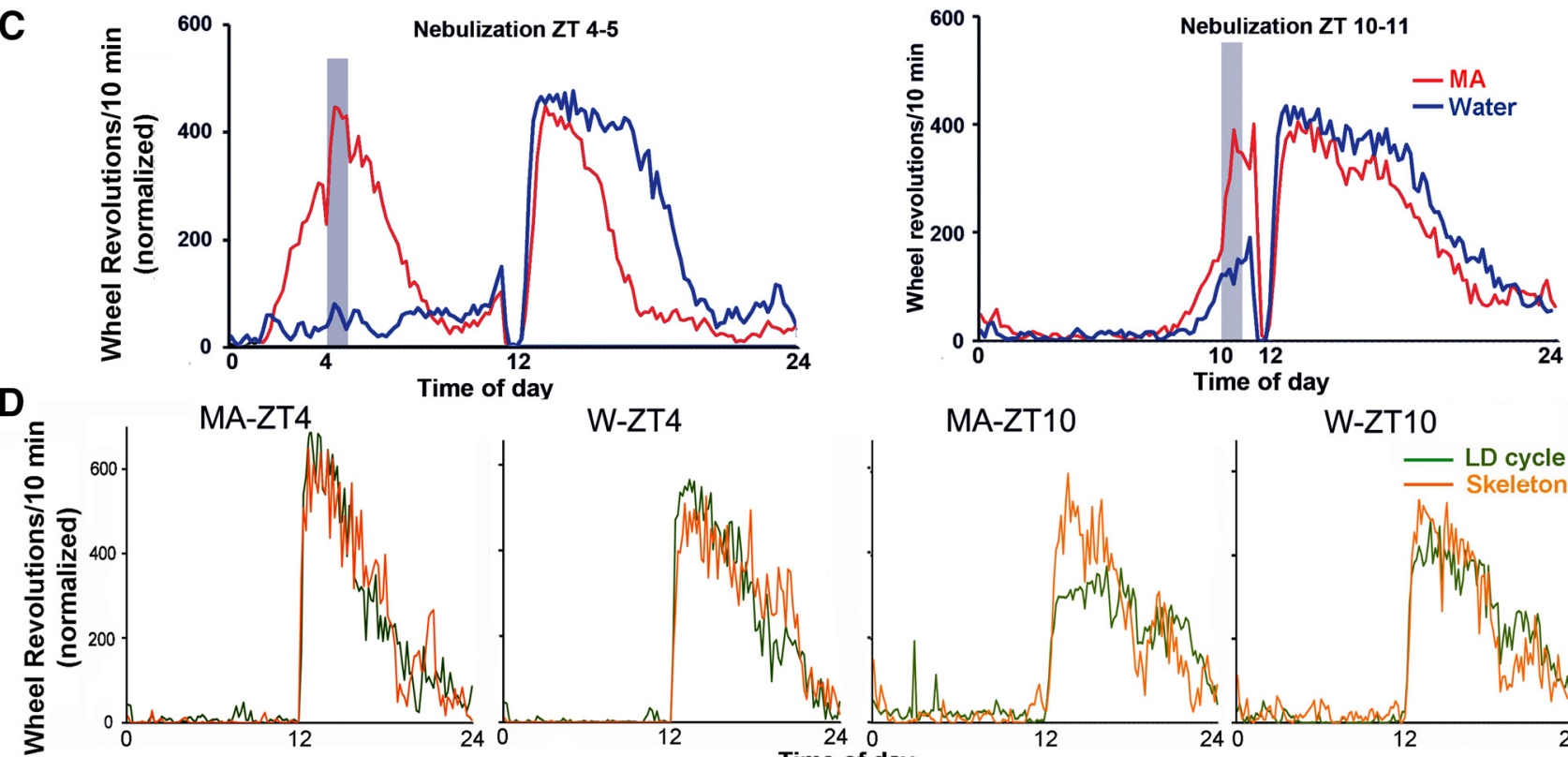

W-ZT4

MA-ZT10

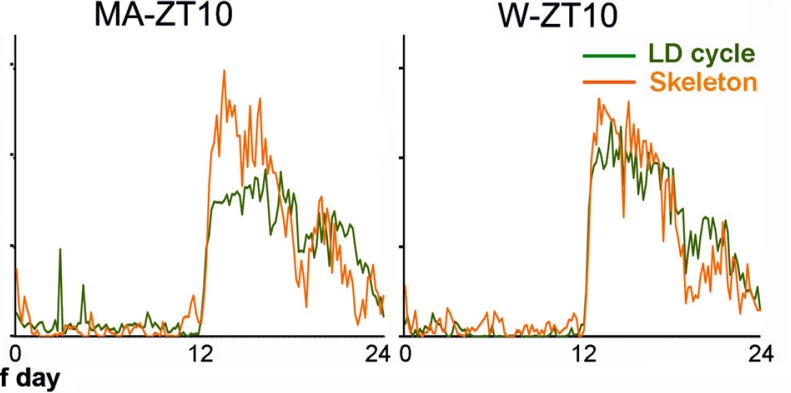

Figure 2. Locomotor activity of mice in each experimental group. A, Actograms of individual mice show the locomotor activity of representative animals in each group; access to nebulized MA or W for $1 \mathrm{~h}$ at ZT4 or at ZT10. Animals were housed in a LD cycle and then in a skeleton photoperiod. The LD cycle and skeleton photoperiods are shown by the horizontal bars in which white denotes day and black denotes night. The vertical black bar on the left of the $y$-axis shows the days used for analysis of locomotor activity. The vertical red (MA) or blue (W) bars within the actograms show the time of daily opening of the tunnel door at either ZT4-ZT5 or ZT10-ZT11 on nebulization days 1-14. B, For individual animals depicted in the actograms in $\boldsymbol{A}$, locomotor activity is shown for each 10-min interval, averaged over days 5-14. C, For all animals in each group, locomotor activity for each 10-min interval was averaged over days 5-14. For comparisons among groups, activity level of each animal is normalized (see methods) to control for differences among individuals in daily amount of running. $\boldsymbol{D}$, Comparison of activity during the 3-d LD cycle shown in the actogram in $\boldsymbol{A}$ and the following 2-d skeleton photoperiod. Analysis was performed as in $\boldsymbol{C}$. The results indicate that the phase of entrainment to LD was not changed when the full photoperiod was replaced by a skeleton photoperiod.

running activity was analyzed for the last $10 \mathrm{~d}$ of the experimental period. Data were not normalized for determination of total daily activity (Fig. $3 B$ ) or when records of individual animals are shown (Fig. 2B).
Perfusion, tissue processing, and staining

Mice were anaesthetized with ketamine-xylazine (100 and $10 \mathrm{mg} / \mathrm{kg}$, respectively; i.p.) at ZT4 or ZT10 and were perfused transcardially with $50 \mathrm{ml}$ of saline solution $(0.9 \%)$ 


\section{A: Anticipatory Activity}

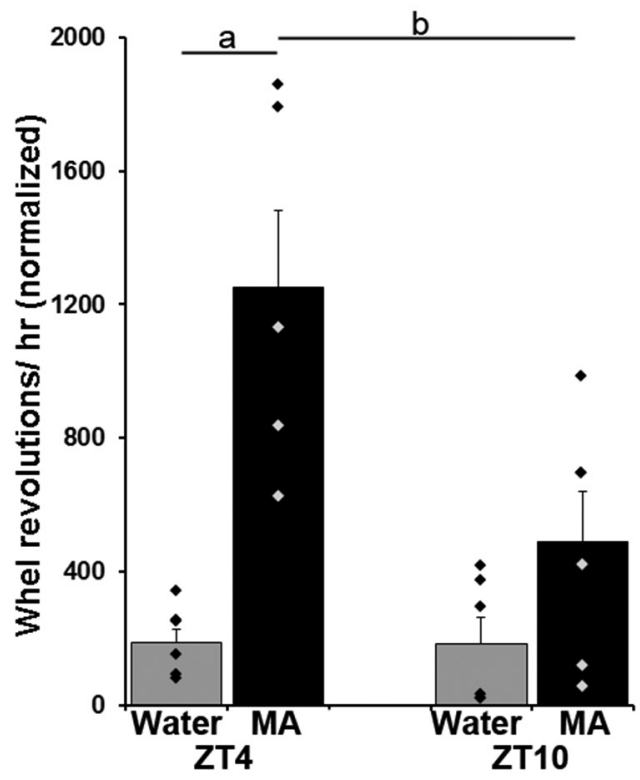

\section{B: Total Daily Activity}

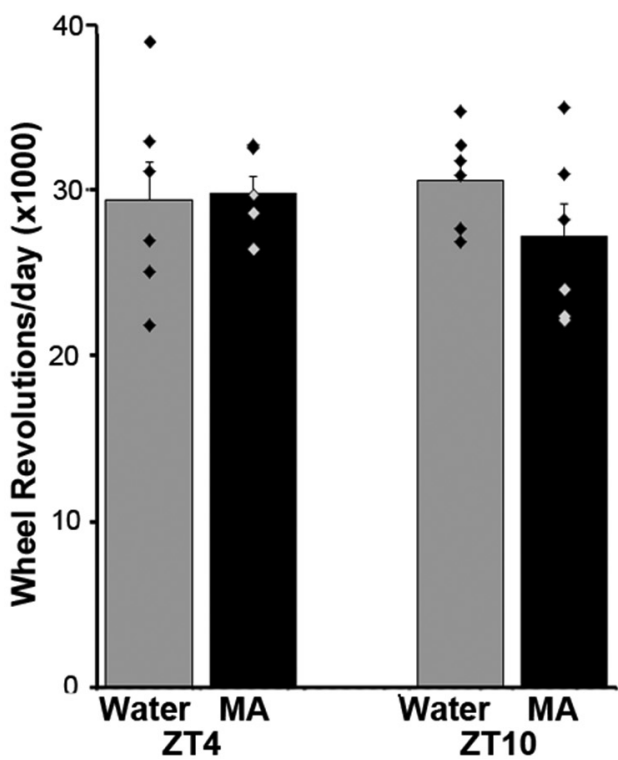

Figure 3. A, Hourly wheel running activity for the 2-h preceding access to the nebulization chamber (normalized, see Materials and Methods). Animals in the MA-ZT4 (black) show more anticipation than W-ZT4 mice (gray; a: Tukey test, $p<0.001$ ). Also, mice run more at ZT4 than at ZT10 in anticipation of access to MA (b: Tukey test, $p=0.002)$. There were no differences in anticipatory activity between MA and water at ZT10 (Tukey test $p=0.134$ ). $\boldsymbol{B}$, Total daily activity (the total number of running wheel revolutions/day is not different among groups (data are not normalized).

followed by $100 \mathrm{ml}$ of $4 \%$ paraformadehyde in phosphate buffer (PB, pH7.3). Brains were removed, postfixed for 24 $\mathrm{h}$ and cryoprotected in $20 \%$ sucrose in PB and sectioned coronally at $50 \mu \mathrm{m}$ in a cryostat (Microm HM 500M) at $-20^{\circ} \mathrm{C}$. For immunohistochemistry, serial coronal sections from the olfactory bulb $(\mathrm{OB})$ to the posterior midbrain were collected in PB, and processed free floating. Every fourth section was used for double-label fluorescence immunostaining of c-FOS and tyrosine hydroxylase (TH). Sections were incubated in blocking solution of normal donkey serum (catalog \#017-000-121 RRID: AB_2337258; Jackson ImmunoResearch) in PB containing $0.3 \%$ of Triton $\mathrm{X}-100$ (PBT $0.3 \%$ ) for $1 \mathrm{~h}$, then incubated for $48 \mathrm{~h}$ at $4^{\circ} \mathrm{C}$ in c-FOS antibody made in rabbit (1:5000; catalog \#sc-52, RRID: AB_2106783; Santa Cruz Biotechnology) and a monoclonal $\mathrm{TH}$ antibody made in mouse (1:5000; catalog \#2294, RRID: AB_572268, Immunostar) diluted in PBT $0.3 \%$. Thereafter, sections were incubated in donkey secondary antibody conjugated to a Cy3 anti-rabbit (catalog \#711-165-152, RRID: $\left.A B \_2307443\right)$ and Cy2 anti-mouse (catalog \#715-225150, RRID:AB_2340826) fluorophores (1:200; Jackson ImmunoResearch) for $2 \mathrm{~h}$, tissue was washed with PBT $0.1 \%$ between incubations. Finally, sections were mounted onto gelatin-subbed slides, dehydrated, cleared in CitriSolv (Fisher Scientific), and coverslipped with Krystalon (EM Diagnostics).

\section{Tissue analysis}

To select brain regions for cell counting of c-FOS cells, two strategies were implemented. First, all sections through the entire brain were scanned to identify regions bearing
c-FOS expression. Next, we examined brain regions previously implicated in studies of anticipatory behaviors for food, drug or other rewards, where c-FOS was measured. Images were captured with a Nikon Eclipse E800 microscope (Nikon) equipped with a cooled CCD camera (Retiga Exi; Q-Imaging), using Q-capture software (RRID: SCR_014432, Q-Imaging) using the excitation wavelengths $480 \pm 20 \mathrm{~nm}$ for Cy2, and $560 \pm 40 \mathrm{~nm}$ for Cy3, with each channel acquired independently and then combined digitally. The localization of nuclei was determined using the mouse brain atlas of (Paxinos and Franklin, 2013). In addition, TH-ir was used to distinguish the nucleus accumbens shell from core and to delineate the ventral tegmental area (VTA) and substantia nigra. For large nuclei, an area in the mid-region of the nucleus was selected for analysis. Images were saved as .tiff files and imported into ImageJ Fiji (RRID:SCR_002285; Schindelin et al., 2012 ) to count c-FOS-ir cells. Two observers blind to the experimental conditions performed the cell counts. Interobserver reliability was $>90 \%$.

The following regions were examined (listed from rostral to caudal, followed by the distance from bregma (Paxinos and Franklin, 2013) used to delineate that region); OB (3.17-2.77), prefrontal cortex (1.77-1.41), orbitofrontal cortex (OFC, 2.33-1.97), lateral septum (LS, 0.61-0.13), dorsal striatum (0.73-0.13), nucleus accumbens core and shell (1.21-0.73), ventral pallidum $(0.61-0.25)$, bed nucleus of the stria terminalis $(0.01$ to -0.35$)$, paraventricular nucleus of thalamus ( -0.35 to -0.45$)$, suprachiasmatic nucleus shell and core $(-0.35$ to -0.59$)$, arcuate nucleus $(-1.55$ to -1.91$)$, lateral hypothalamus $(\mathrm{LH},-0.47$ to $-1.07)$, dorsomedial hypothalamic nucleus $(\mathrm{DMH},-1.43$ 
to -1.91$)$, ventromedial hypothalamic nucleus $(-1.43$ to -1.91 ), dentate gyrus of the hippocampus (DG, -1.79 to $-2.45)$, insula $(-0.59$ to -1.23$)$, habenula $(-1.23$ to -1.91), basolateral, basomedial, central and medial amygdala $(-1.07$ to -2.03$)$, ventral posteriomedial nucleus of the thalamus $(-1.07$ to -1.91$)$, piriform cortex $(-1.07$ to -1.91$)$, periaqueductal gray $9-3.07$ to -3.51$)$, VTA, substantia nigra $(-2.91$ to -3.15$)$, and supramammillary nucleus $(-2.8$ to -2.9$)$. For each brain region, images taken from each side of three brain sections (six images) were scored for each animal, except for nuclei with a small rostro-caudal extent (paraventricular nucleus of thalamus, suprachiasmatic nucleus, supramammillary nucleus), where two brain sections (four images) were analyzed for each animal. c-FOS-positive cells in each brain region are reported as number of cells $/ \mathrm{mm}^{2}$.

\section{Statistical analyses}

Differences in anticipatory activity and in number of c-FOS-ir cells among the four groups (MA-ZT4, W-ZT4, MA-ZT10, and W-ZT10) were compared by two-way ANOVA (W or MA treatment) $\times$ (time of day), followed by Tukey post hoc test. Daily changes in anticipatory activity were evaluated by two-way repeated measures ANOVA. Correlation between activity levels and c-FOS was assessed by Pearson Product Moment. All analyses were done using SigmaStat 2.03 (RRID:SCR_010285, SPSS Inc.).

\section{Results}

\section{Experiment 1: anticipatory behavior}

The first goal was to assess the influence of treatment effects on anticipatory behavior and to determine whether the time of day modulated the anticipatory response to MA or water. During the experiments, nebulized MA or water was available in the nebulization chamber at either ZT4 or ZT10. The hypothesis was that an effect of time of day in the $W$ group would point to a drug-independent circadian effect of anticipation, while a difference in responding at ZT4 versus ZT10 in the MA group would suggest a time of day effect of the drug. Interaction effects would suggest that the effect of MA is modulated by time of day, pointing to a role of circadian timing in anticipation of MA behavior. Figure 2 shows the daily activity of representative individuals over the entire experiment (Fig. 2A), these representative animals' activity profiles during the last 10 experimental days (Fig. $2 B$ ), and for the group as a whole (Fig. $2 C$ ) summed over the last 10 experimental days. It is evident that after a few days of MA availability, mice develop anticipatory behavior, especially at ZT4 and much less at ZT10. Activity increased during and immediately after the time of MA nebulization, followed by a period of inactivity during the day. Nocturnal activity onset was not shifted by the skeleton photoperiod and during the nebulization period (Fig. 2D). Animals do not show anticipatory activity for available nebulized water, and the usual preference for activity during the nighttime is seen in all four groups.

Quantification of the results on locomotor activity before the availability of the material in the nebulization chamber, and total amount of daily activity is shown in
Figure 3. The mice awaken and show more anticipation of MA availability before door opening at ZT4 than at ZT10, while they do not anticipate water availability at either time (Fig. 3A; main effects: MA vs water, $F_{(1,22)}=23.52 ; p<$ 0.001 ; time of day, ZT4 vs ZT10, $F_{(1,22)}=7.26 ; p=0.014$; interaction, $\left.F_{(1,22)}=7.23 ; p=0.014\right)$. Although anticipatory activity for MA is greater at ZT4 than at ZT10, the amount of time spent in the nebulizing chamber does not differ between these groups (ZT4: $138.4 \pm 25.5 \mathrm{~s}$; ZT10: $\left.128.0 \pm 16.0 \mathrm{~s} ; t_{(9)}=0.36, p=0.73\right)$. Furthermore, there were no differences among groups in total amount of daily activity (Fig. $3 B$; main effect: MA vs water, $F_{(1,22)}=0.68$; $p=0.42$; time of day, ZT4 vs ZT10, $F_{(1,22)}=0.18 ; p=$ 0.68 ; treatment $\times$ time of day interaction, $F_{(1,22)}=1.19$; $p=0.29$ ). This can be seen in the actograms of Figure 2, mice reduce nocturnal activity when they increase MAassociated diurnal activity, keeping total daily activity unchanged.

\section{Experiment 2: c-FOS expression in brain}

The behavioral data point to a main effect of treatment, time of day, and an interaction effect on anticipatory behavior. Thus, we aimed to identify brain areas that expressed c-FOS in the same manner, specifically those in which there was higher c-FOS expression with MA than water anticipation (drug effect), and more at ZT4 than ZT10 (time effect) and an interaction (anticipation effect). The c-FOS counts for all brain regions studied are shown in Figures $4 B, 5 B$ and Table 1. Statistical analysis (two-way ANOVA followed by the Tukey test) for the foregoing regional effects are shown in Table 2.

Two brain regions met all the aforementioned criteria: OFC (treatment: $F_{(1,22)}=14.45 p=0.001$; time: $F_{(1,22)}=$ $11.56 p=0.003$; interaction: $\left.F_{(1,22)}=7.52 p=0.013\right)$; $\mathrm{DMH}$ (treatment: $F_{(1,22)}=9.99, p=0.005$; time: $F_{(1,22)}=$ 5.46, $p=0.031$; interaction: $\left.F_{(1,22)}=5.15, p=0.035\right)$. In the LS there were significant main effects, while interaction effects were marginally significant (treatment: $F_{(1,22)}=$ $30.81, p<0.001$; time: $F_{(1,22)}=9.11, p=0.007$; interaction $\left.F_{(1,22)}=3.92, p=0.063\right)$. In the OFC, c-FOS was densely expressed in the medial and ventral regions and more sparsely in the lateral region. c-FOS was expressed throughout the DMH. In the LS, c-FOS was expressed throughout the nucleus but more densely in the ventral region.

The results for these brain regions are shown in the photomicrographs (Fig. 4A) and the quantitative analysis is shown in the bar charts below the photomicrographs (Fig. 4B).

We also noted three brain regions, the OB, LH, and DG, where both the main effects of treatment and time of day were significant, but with no interaction effects (Fig. 5; Table 2). In the OB c-FOS was expressed in the glomerular, mitral and granule layers (OB: treatment: $F_{(1,22)}=$ $7.01, p=0.016$; time: $F_{(1,22)}=17.29, p<0.001$; interaction: $\left.F_{(1,22)}=1.71, p=0.207\right)$. In the LH, c-FOS expression occurred throughout the nucleus (treatment: $F_{(1,22)}=$ 12.3, $p=0.002$; time: $F_{(1,22)}=18.98, p<0.001$; interaction: $\left.F_{(1,22)}=5 \mathrm{E}^{-4}, p=0.982\right)$, and in the DG c-FOS was expressed in the granular layer (treatment: $F_{(1,22)}=28.98$, 

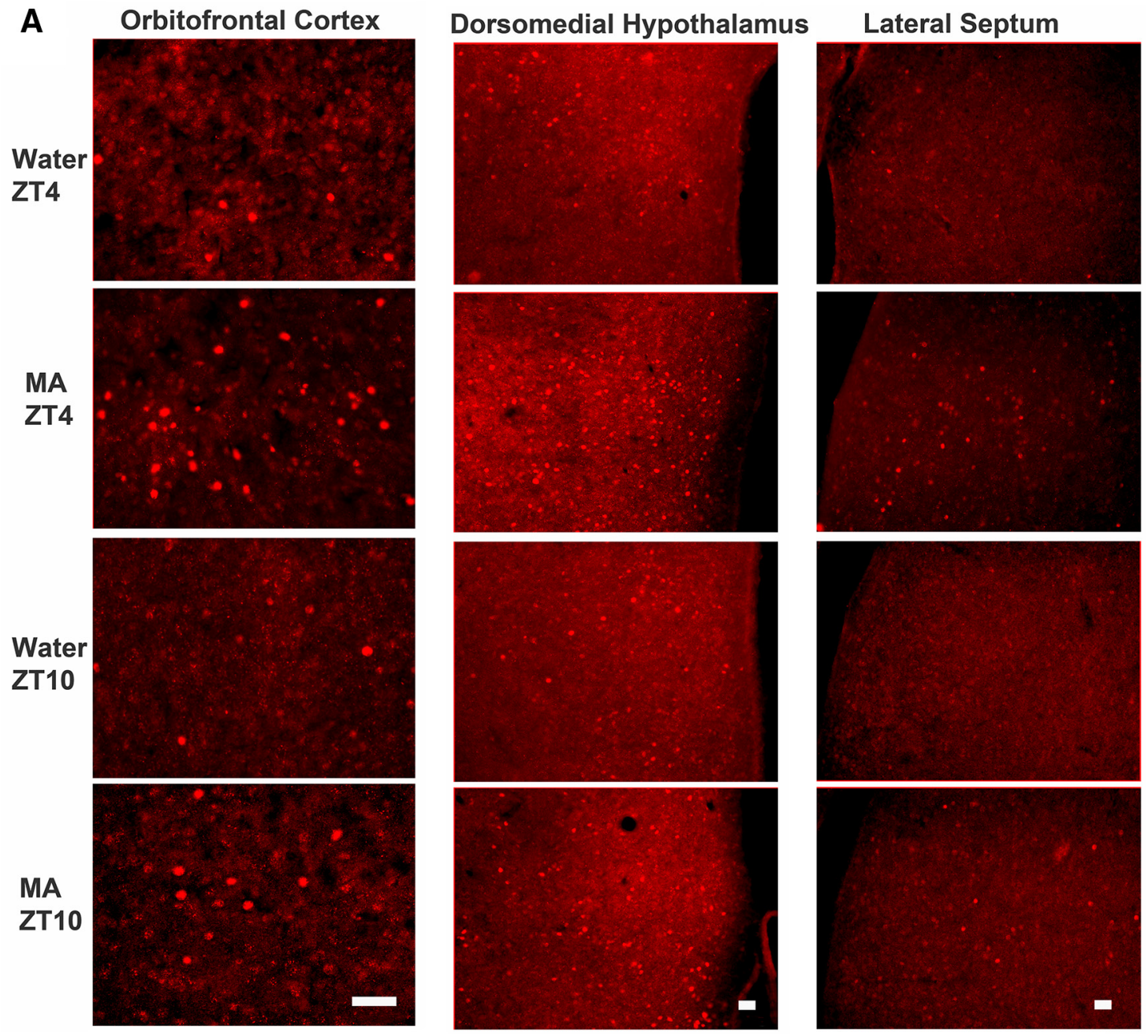

B Orbitofrontal Cortex
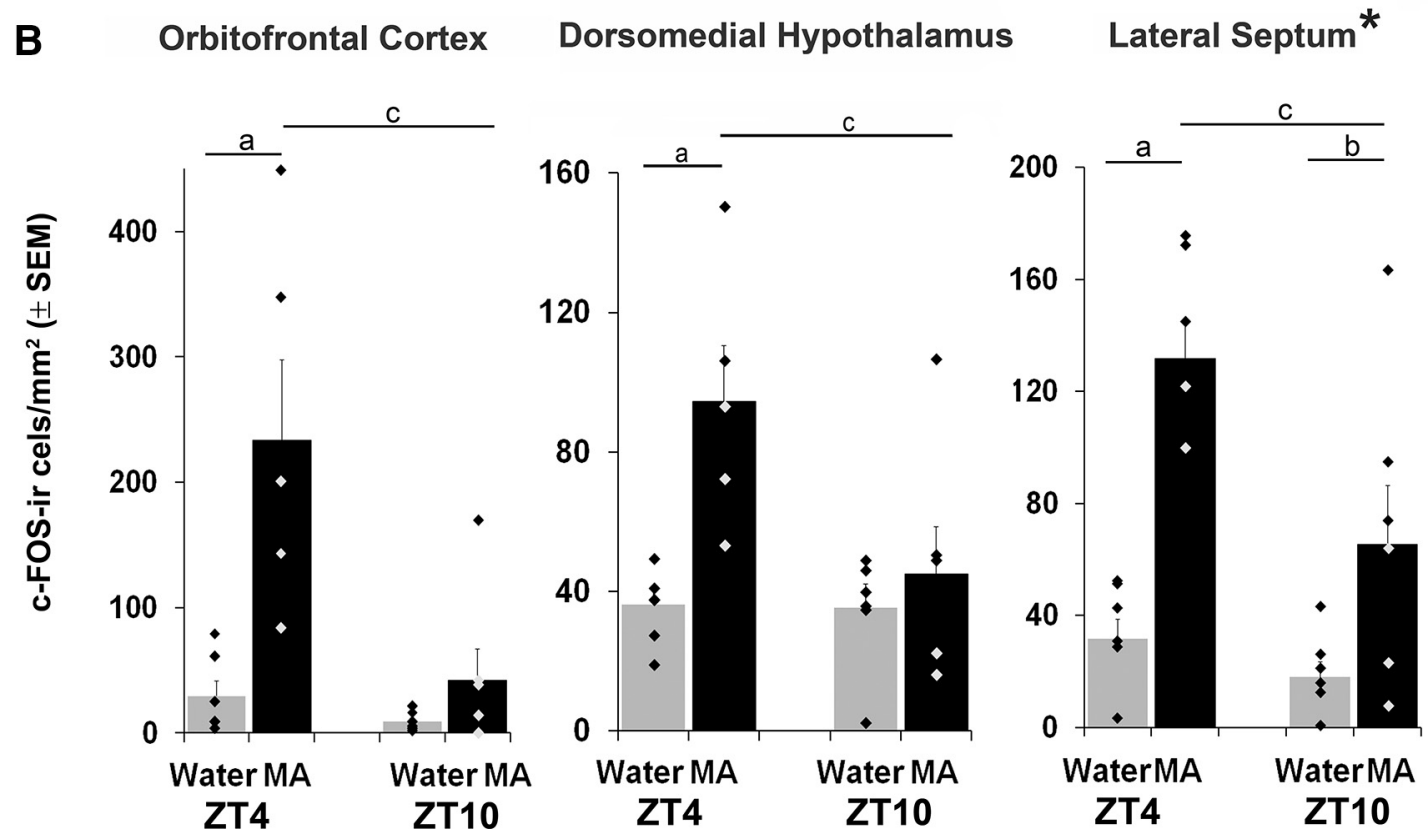

Figure 4. A, Photomicrographs show c-FOS expression in brain areas where there is an effect of treatment, time of day and interaction in animals sacrificed at ZT4 or ZT10. Scale bars: $50 \mu \mathrm{m}$. B, Bar graphs show the number of c-FOS-positive cells in brain regions corresponding to the photomicrographs in $\boldsymbol{A}$. Water = gray bars, MA = black bars; significant difference in Tukey tests where a, ZT4 
continued

MA versus W; b, ZT10 MA versus W; c, MA ZT4 versus 10; * indicates that the interaction effect for the LS was marginally significant at $p=0.06$ (Table 2).

$p<0.001$; time: $F_{(1,22)}=10.12, p=0.005$; interaction: $\left.F_{(1,22)}=1.98, p=0.176\right)$. This was interpreted to indicate that MA and time of day both contribute to c-FOS expression levels in these brain regions, but there was no evidence of an effect of anticipation in a manner that paralleled the behavior.

For the other brain regions examined, c-FOS expression in the medial amygdala and the ventral posteromedial thalamus was higher in the MA than in the W groups, but there was no effect of time of day. c-FOS expression was higher at ZT4 than ZT10 in the paraventricular nucleus of the thalamus, suprachiasmatic nucleus shell and arcuate nucleus, but there was no difference between MA and $\mathrm{W}$ groups in these brain regions. Regions with neither treatment nor time of day effects include: the suprachiasmatic nucleus core, the basolateral, basomedial and central amygdala, the periacqueductal gray, the piriform cortex and the supramammillary nucleus. Finally, there was little or no c-FOS detected in the prefrontal cortex, insula, dorsal striatum, nucleus accumbens shell or core, ventral pallidum, bed nucleus of the stria terminalis, VTA, substantia nigra, or habenula.

Table 1 shows the c-FOS cell counts for all brain regions for which there were significant treatment (alone) or time of day effects (alone). There were no interaction effects in these brain regions; ${ }^{\top}$ indicates that the area of the nucleus was traced manually, and ${ }^{a}$ indicates that a fixed area was measured.

\section{c-FOS is not correlated with amount of locomotor activity}

Finally, we examined whether the intensity of wheelrunning itself could produce c-FOS expression by evaluating the correlation between amount of anticipatory locomotor activity (\# wheel rotations before nebulization, data not normalized) and c-FOS expression (Table 3). In the water available groups, anticipatory activity ranged from 7.6 to 409.6 revolutions/h, and no significant correlations were found in any brain region. Similarly, in the MA groups, anticipatory activity ranged from 47 to $1800 \mathrm{rev}$ olutions/h, and there was no evidence of a correlation between activity and number of c-FOS-positive neurons, except for the piriform cortex, a brain region in which there was no effect of either time of day or treatment.

\section{Discussion}

\section{Overview}

A major function of the CNS is to anticipate and predict upcoming events. Our results present a number of novel findings on the nature of anticipation and its neural basis, evaluated in a noninvasive voluntary intake protocol. First, mice developed anticipatory behavior before the availability of MA but not in anticipation of nebulized water. When MA was available during the day, mice awoke during their normal sleep time and ran in the home cage wheel for $\sim 2$ $\mathrm{h}$ in anticipation of an upcoming interval of MA availability, with more anticipation in early versus late day. When nebulized water was available in the chamber, the mice did not develop anticipatory behavior. Three brain regions were implicated in the anticipatory response, namely the OFC, LS, and DMH. Here the patterns of c-FOS expression paralleled the anticipatory behavior. The present evidence points to CNS sites of cFos expression before MA availability, and highlights the usefulness of behavioral anticipatory responses in identifying activated brain regions. That said, the c-Fos expression seen here might reflect neural activity associated with or causal to behavioral anticipation, or causal to physiologic anticipation (e.g., autonomic outflow, peripheral hormones, etc.), or it might reflect neural activity in response to behavioral, endocrine, thermal or other anticipatory changes. These possibilities cannot be distinguished in the current experiment, nor are they necessarily separable.

The engagement of the OFC in MA anticipation is interesting as it has been implicated in the processing of signals involved in the reward value of odor, taste or touch (O'Doherty et al., 2000; Rolls, 2000). The OFC receives a dopaminergic projection from the VTA (Berger et al., 1991; Dunnett and Robbins, 1992). Variation in dopamine transporter function in OFC is associated with impulsive action (Yates et al., 2016). DA antagonists alter connectivity patterns in the OFC (Kahnt and Tobler, 2017) and decrease motivation for reward (Cetin et al., 2004). The OFC shows c-FOS activation in anticipation of a daily meal and, not surprisingly, even more activation when sucrose is added to the meal (Mitra et al., 2011). OFC has been implicated as a locus of relative value and of expected or outcomes (Izquierdo, 2017). Finally, the OFC has been implicated in drug addiction in preclinical and clinical studies (Schoenbaum and Shaham, 2008). Neural activation in the OFC increases in response to drugs (Volkow and Fowler, 2000; Guillem et al., 2017) and metabolic activity is proportional to the intensity of craving in humans (Volkow and Fowler, 2000). Taken together, the evidence suggests that the OFC can track the reward value of drugs and that its activity is associated with anticipation.

The finding that the $\mathrm{DMH}$ is involved in the timing of circadian responses is consistent with numerous reports in the food anticipation literature. (Angeles-Castellanos et al., 2004; Gooley et al., 2006; Poulin and Timofeeva, 2008; Mitra et al., 2011; Blum et al., 2012; Luna-lllades et al., 2017). The DMH has been implicated in feeding behavior and body weight regulation (Bellinger and Bernardis, 2002). However, the DMH does not seem to be the sole necessary brain nucleus for these responses, as $\mathrm{DMH}$-lesions do not eliminate food anticipation (Landry et al., 2006; Landry et al., 2007). Activation of the DMH reflects the presence of food, evidenced by increases in c-FOS expression in anticipation of meals. This activation persists for several days at the previous time of food 

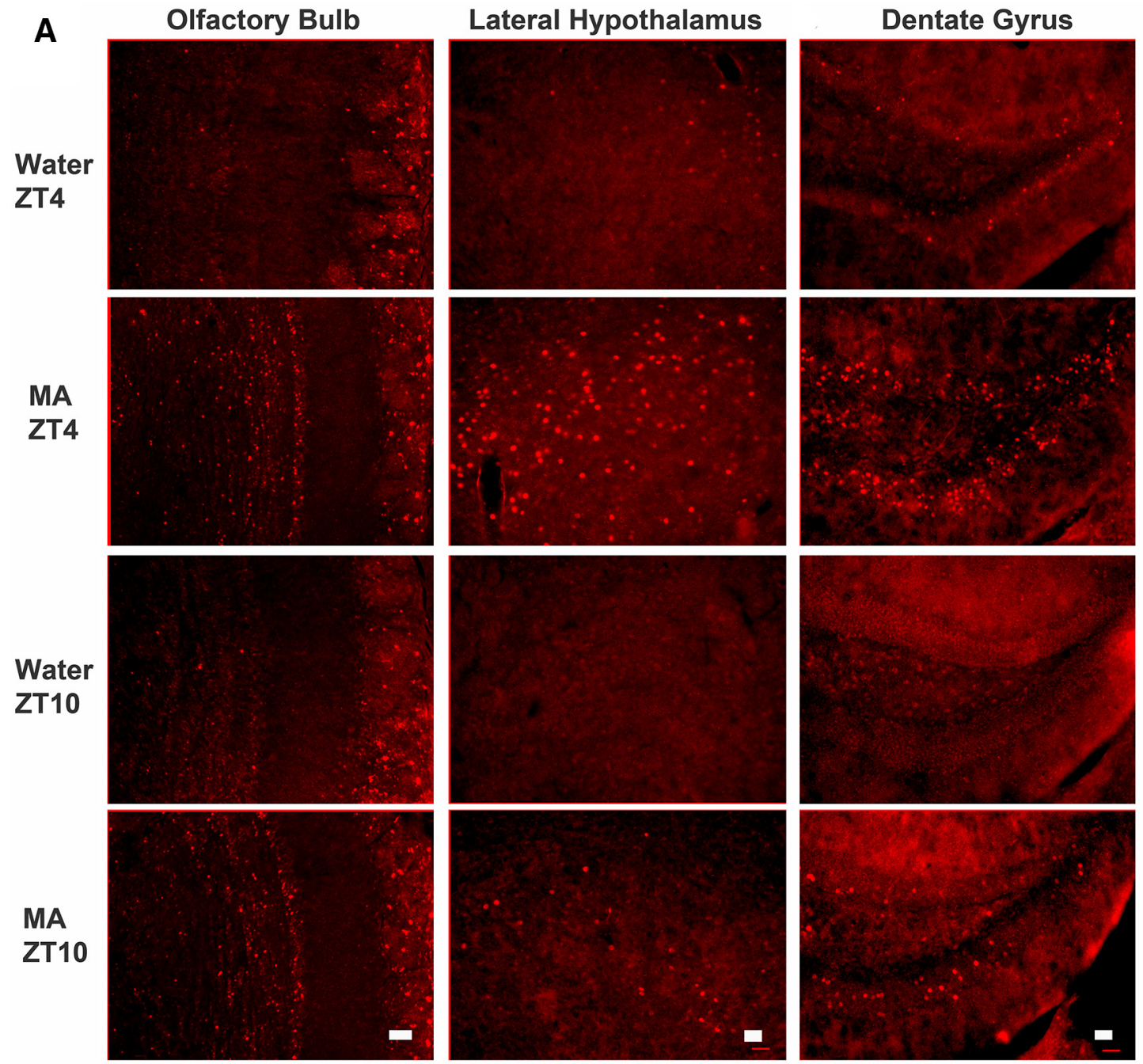

B

Olfactory Bulb

Lateral Hypothalamus

\section{Dentate Gyrus}
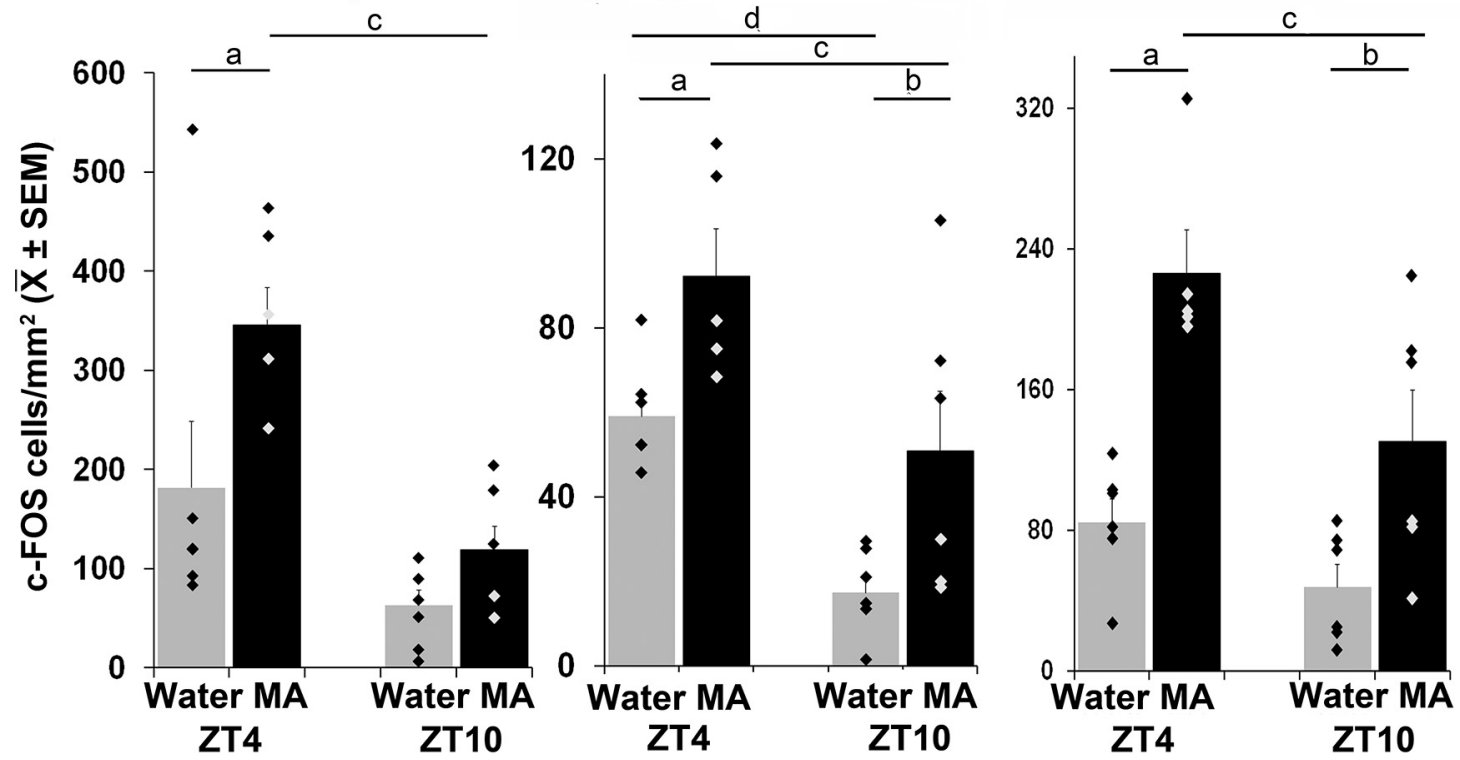

Figure 5. A, Photomicrographs show c-FOS expression in representative brain areas where there is an effect of both treatment and time of day but no interaction. Scale bars: $50 \mu \mathrm{m}$. B. Bar graphs show the number of c-FOS-positive cells in brain regions 
continued

corresponding to the photomicrographs in $\boldsymbol{A}$. Water = gray bars, MA = black bars; significant difference in Tukey tests where a, ZT4 MA versus W; b, ZT10 MA versus W; c, MA ZT4 versus 10; d, W-ZT4 versus 10 (Table 2).

anticipation when ad libitum access to food is restored (Angeles-Castellanos et al., 2004; Blum et al., 2012). Orexin neurons in $\mathrm{DMH}$ may play a role in anticipation, as food anticipatory activity is significantly diminished in mice lacking orexin neurons (Akiyama et al., 2004). Fur- thermore substantial evidence points to a role for orexin in modulating motivational, self-administration and reinstatement of drugs (James et al., 2017), possibly through actions on the mesolimbic dopamine system (Calipari and Espana, 2012).

Table 1. Number of c-FOS positive neurons in brain regions not shown in figures 4,5 .

\begin{tabular}{|c|c|c|c|c|}
\hline Brain Regions & \multirow{2}{*}{ W-ZT4 } & \multirow{2}{*}{ MA-ZT4 } & \multirow{2}{*}{ W-ZT10 } & \multirow{2}{*}{ MA-ZT10 } \\
\hline Regions with treatment effects & & & & \\
\hline Medial Amygdala $^{\top}$ & $27.4 \pm 3.5$ & $51.4 \pm 6.8$ & $25.3 \pm 3.9$ & $38.1 \pm 8.5$ \\
\hline Ventral Posteromedial Thalamus ${ }^{a}$ & $13.9 \pm 8.1$ & $445.9 \pm 141.9$ & $9.5 \pm 6.4$ & $235.2 \pm 123.8$ \\
\hline \multicolumn{5}{|l|}{ Regions with time of day effects } \\
\hline $\begin{array}{l}\text { Paraventricular Nucleus of the } \\
\text { Thalamus }^{{ }^{3}}\end{array}$ & $316.1 \pm 43.4$ & $362.2 \pm 52.2$ & $246.4 \pm 39.3$ & $231.7 \pm 44.4$ \\
\hline Suprachiasmatic Nucleus $(\text { Shell })^{\top}$ & $222.1 \pm 27.0$ & $190.4 \pm 26.2$ & $108.5 \pm 23.5$ & $114.2 \pm 21.0$ \\
\hline Arcuate Nucleus $^{\top}$ & $19.8 \pm 2.5$ & $16.7 \pm 4.5$ & $9.2 \pm 3.6$ & $10.5 \pm 3.8$ \\
\hline \multicolumn{5}{|c|}{$\begin{array}{l}\text { Regions with no effects of treatment } \\
\text { or time }\end{array}$} \\
\hline Suprachiasmatic Nucleus (Core) ${ }^{\top}$ & $212.5 \pm 27.9$ & $142.8 \pm 46.4$ & $172.8 \pm 67.6$ & $205.4 \pm 70.9$ \\
\hline Basolateral Amygdala ${ }^{a}$ & $13.8 \pm 4.0$ & $19.4 \pm 6.5$ & $15.4 \pm 4.6$ & $15.1 \pm 6.4$ \\
\hline Basomedial Amygdala $^{a}$ & $20.9 \pm 5.2$ & $24.4 \pm 6.7$ & $15.8 \pm 3.5$ & $27.4 \pm 9.0$ \\
\hline Central Amygdala $^{a}$ & $27.7 \pm 5.8$ & $35.3 \pm 4.1$ & $24.5 \pm 4.5$ & $38.4 \pm 12.3$ \\
\hline Periacqueductal gray ${ }^{a}$ & $27.5 \pm 6.7$ & $76.4 \pm 40.1$ & $38.4 \pm 12.1$ & $52.8 \pm 22.5$ \\
\hline Piriform Cortex ${ }^{a}$ & $112.3 \pm 37.4$ & $214.6 \pm 85.0$ & $70.0 \pm 21.3$ & $145.8 \pm 65.9$ \\
\hline Supramammillary Nucleus ${ }^{a}$ & $38.4 \pm 11.2$ & $90.2 \pm 30.5$ & $59.6 \pm 45.0$ & $64.5 \pm 25.6$ \\
\hline
\end{tabular}

\begin{tabular}{|c|c|c|c|c|c|c|c|c|c|}
\hline \multirow[t]{2}{*}{ Brain area } & \multicolumn{2}{|c|}{ Drug effect } & \multicolumn{2}{|c|}{ Time of day effect } & Drug*Time of day & \multicolumn{3}{|c|}{ Post hoc (Tukey test) } & \multirow[b]{2}{*}{$\begin{array}{l}\text { ZT10: } \\
\text { MA vs W }\end{array}$} \\
\hline & & & & & & $\begin{array}{l}\text { MA: ZT4 } \\
\text { vs ZT10 }\end{array}$ & $\begin{array}{l}\text { W: ZT4 } \\
\text { vs ZT10 }\end{array}$ & $\begin{array}{l}\text { ZT4: } \\
\text { MA vs W }\end{array}$ & \\
\hline Olfactory bulb & $F_{1,22}=7.01$ & $p=0.016$ & $F_{1,22}=17.29$ & $\mathrm{p}<0.001$ & $F_{1,22}=1.71 \quad p=0.207$ & $p=0.001$ & $\mathrm{p}=0.053$ & $\mathrm{p}=0.013$ & $\mathrm{p}=0.344$ \\
\hline Orbitofrontal cortex & $F_{1,22}=14.45$ & $\mathrm{p}=0.001$ & $F_{1,22}=11.56$ & $\mathrm{p}=0.003$ & $F_{1,22}=7.52 p=0.013$ & $\mathrm{p}<0.001$ & $\mathrm{p}=0.639$ & $\mathrm{p}<0.001$ & $\mathrm{p}=0.452$ \\
\hline Lateral Septum & $F_{1,22}=30.81$ & $\mathrm{p}<0.001$ & $F_{1,22}=9.11$ & $\mathrm{p}=0.007$ & $F_{1,22}=3.92 p=0.063$ & $\mathrm{p}=0.003$ & $\mathrm{p}=0.461$ & $\mathrm{p}<0.001$ & $\mathrm{p}=0.018$ \\
\hline Lateral hypothalamus & $F_{1,22}=12.3$ & $\mathrm{p}=0.002$ & $F_{1,22}=18.98$ & $\mathrm{p}<0.001$ & $\mathrm{~F}_{1,22}=5 \mathrm{E}^{-4} \quad \mathrm{p}=0.982$ & $\mathrm{p}=0.008$ & $\mathrm{p}=0.005$ & $p=0.027$ & $\mathrm{p}=0.020$ \\
\hline $\begin{array}{l}\text { Dorsomedial hypothalamic } \\
\text { nucleus }\end{array}$ & $F_{1,22}=9.99$ & $\mathrm{p}=0.005$ & $\mathrm{~F}_{1,22}=5.46$ & $\mathrm{p}=0.031$ & $\mathrm{~F}_{1,22}=5.15 \mathrm{p}=0.035$ & $\mathrm{p}=0.005$ & $\mathrm{p}=0.961$ & $\mathrm{p}=0.002$ & $\mathrm{p}=0.525$ \\
\hline Dentate gyrus & $F_{1,22}=28.98$ & $\mathrm{p}<0.001$ & $F_{1,22}=10.12$ & $\mathrm{p}=0.005$ & $F_{1,22}=1.98 \quad p=0.176$ & $\mathrm{p}=0.005$ & $\mathrm{p}=0.214$ & $\mathrm{p}<0.001$ & $\mathrm{p}=0.010$ \\
\hline $\begin{array}{l}\text { Medial amygdala } \\
\text { Ventroposteromedial of }\end{array}$ & $F_{1,22}=9.43$ & $\mathrm{p}=0.006$ & $\mathrm{~F}_{1,22}=1.67$ & $\mathrm{p}=0.212$ & $\mathrm{~F}_{1,22}=0.88 \quad \mathrm{p}=0.361$ & $\mathrm{p}=0.141$ & $\mathrm{p}=0.799$ & $\mathrm{p}=0.012$ & $\mathrm{p}=0.139$ \\
\hline $\begin{array}{l}\text { thalamus } \\
\text { Paraventricular nucleus of }\end{array}$ & $F_{1,22}=13.57$ & $\mathrm{p}=0.002$ & $F_{1,22}=1.45$ & $\mathrm{p}=0.243$ & $F_{1,22}=1.34 \quad p=0.262$ & $\mathrm{p}=0.120$ & $\mathrm{p}=0.972$ & $\mathrm{p}=0.004$ & $\mathrm{p}=0.083$ \\
\hline $\begin{array}{l}\text { Thalamus } \\
\text { Suprachiasmatic nucleus }\end{array}$ & $\mathrm{F}_{1,22}=0.12$ & $\mathrm{p}=0.730$ & $F_{1,22}=5.03$ & $p=0.037$ & $\mathrm{~F}_{1,22}=0.46 \mathrm{p}=0.505$ & $\mathrm{p}=0.058$ & $\mathrm{p}=0.272$ & $\mathrm{p}=0.485$ & $\mathrm{p}=0.814$ \\
\hline Shell & $F_{1,22}=0.28$ & $\mathrm{p}=0.603$ & $F_{1,22}=14.95$ & $\mathrm{p}=0.001$ & $F_{1,22}=0.58 \quad p=0.455$ & $\mathrm{p}=0.045$ & $\mathrm{p}=0.003$ & $\mathrm{p}=0.383$ & $\mathrm{p}=0.868$ \\
\hline Core & $F_{1,22}=0.11$ & $\mathrm{p}=0.749$ & $F_{1,22}=0.04$ & $\mathrm{p}=0.843$ & $F_{1,22}=0.80 \quad p=0.382$ & & & & \\
\hline Arcuate Nucleus & $F_{1,22}=0.07$ & $\mathrm{p}=0.790$ & $F_{1,22}=5.4$ & $\mathrm{p}=0.031$ & $F_{1,22}=0.37 \quad p=0.549$ & $\mathrm{p}=0.251$ & $p=0.047$ & $\mathrm{p}=0.550$ & $\mathrm{p}=0.808$ \\
\hline Basolateral amygdala & $F_{1,22}=0.24$ & $\mathrm{p}=0.633$ & $F_{1,22}=0.06$ & $\mathrm{p}=0.804$ & $F_{1,22}=0.30 \quad p=0.593$ & & & & \\
\hline Basomedial amygdala & $\mathrm{F}_{1,22}=1.37$ & $\mathrm{p}=0.256$ & $\mathrm{~F}_{1,22}=0.02$ & $\mathrm{p}=0.878$ & $\mathrm{~F}_{1,22}=0.39 \quad \mathrm{p}=0.537$ & & & & \\
\hline Central amygdala & $\mathrm{F}_{1,22}=1.94$ & $\mathrm{p}=0.180$ & $\mathrm{~F}_{1,22}=5 \mathrm{E} 10^{-5}$ & $\mathrm{p}=0.994$ & $\mathrm{~F}_{1,22}=0.17 \quad \mathrm{p}=0.684$ & & & & \\
\hline Periaqueductal gray & $F_{1,22}=2.06$ & $\mathrm{p}=0.168$ & $F_{1,22}=0.08$ & $p=0.776$ & $F_{1,22}=0.61 \quad p=0.444$ & & & & \\
\hline Piriform cortex & $F_{1,22}=2.60$ & $\mathrm{p}=0.123$ & $F_{1,22}=1.01$ & $\mathrm{p}=0.327$ & $F_{1,22}=0.06 p=0.813$ & & & & \\
\hline Supramammillary nucleus & $F_{1.22}=0.85$ & $\mathrm{p}=0.368$ & $F_{1,22}=0.01$ & $\mathrm{p}=0.944$ & $\mathrm{~F}_{1,22}=0.58 \quad \mathrm{p}=0.455$ & & & & \\
\hline
\end{tabular}


Table 3. Pearson product moment correlations between anticipatory wheel running and c-FOS expression

\begin{tabular}{lll}
\hline Brain areas & MA group $(n=11)$ & Water group $(n=12)$ \\
OB & $r=0.55 p=0.08$ & $r=0.28 p=0.37$ \\
OFC & $r=0.55 p=0.08$ & $r=0.15 p=0.64$ \\
LS & $r=0.25 p<0.46$ & $r=0.26 p=0.42$ \\
LH & $r=0.37 p=0.26$ & $0.14 p=0.66$ \\
DMH & $r=0.19 p=0.58$ & $r=0.29 p=0.36$ \\
DG & $r=0.55 p=0.08$ & $r=0.01 p=0.98$ \\
Medial amygdala & $r=0.06 p=0.87$ & $r=0.38 p=0.22$ \\
Ventroposteromedial of thalamus & $r=0.59 p=0.06$ & $r=0.08 p=0.80$ \\
Paraventricular nucleus of thalamus & $r=0.49 p=0.13$ & $r=0.35 p=0.27$ \\
Suprachiasmatic nucleus & & $r=0.33 p=0.30$ \\
$\quad$ Shell & $r=0.15 p=0.66$ & $r=0.11 p=0.75$ \\
$\quad$ Core & $r=0.08 p=0.82$ & $r=0.48 p=0.11$ \\
Basolateral amygdala & $r=0.03 p=0.93$ & $r=0.08 p=0.81$ \\
Basomedial amygdala & $r=0.04 p=0.89$ & $r=0.12 p=0.70$ \\
Central amygdala & $r=0.04 p=0.91$ & $r=0.33 p=0.29$ \\
Periaqueductal gray & $r=0.03 p=0.94$ & $r=0.47 p=0.13$ \\
Piriform cortex & $r=0.62 p=0.04$ & $r=0.40 p=0.20$ \\
Supramammillary nucleus & $r=0.13 p=0.70$ & \\
& & \\
\hline
\end{tabular}

We found that c-FOS in the LS was activated more in MA than in $W$ groups and more in early than late day, though interaction effects were marginally significant. A role for the LS in anticipation is consistent with work showing that MA seeking increases c-FOS expression in the LS (Cornish et al., 2012) and that withdrawal of selfadministered MA is associated with activation of the septum, among other regions, suggesting a role in "craving" (Cornish et al., 2012). That LS stimulation is rewarding has long been known (Olds and Milner, 1954; Randt and Quartermain, 1972; Sheehan et al., 2004). The LS has connections with the mesocorticolimbic dopamine system, thereby regulating motivation. The LS can stimulate the activity of midbrain dopamine neurons and regulate the consequences of this activity on the ventral striatum (Sheehan et al., 2004). Prior work using c-FOS activation as a measure has strongly implicated the mesolimbic circuit in anticipatory behavior. The LS has also been implicated in addiction to several drugs of abuse: mice self-administer morphine into the LS, a response blocked by dopamine or opiate antagonists (Le Merrer et al., 2007). Inactivation of LS neurons attenuate context- and cue-induced reinstatement of cocaine seeking (McGlinchey and Aston-Jones, 2017) and inactivation of the Ca3-LS-VTA circuit blocks context-induced reinstatement of cocaine seeking (Luo et al., 2011; McGlinchey and Aston-Jones, 2017).

One puzzling aspect of the present work is that we have not found evidence of anticipation, using the c-FOS marker, in many of the brain areas identified in prior studies. A possible explanation can be species differences, as little of the prior work had been done on mice. Alternatively, there are substantial differences among studies in their experimental designs. Many prior studies examine food anticipation and it is generally accepted that food anticipation is affected by the size and the interval since the last meal (Strubbe and Woods, 2004), factors not involved in MA anticipation. However, even within studies of drugs, identification of brain regions mediating anticipation are mixed (Neisewander et al., 2000; Rhodes et al., 2005;
Cornish et al., 2012; Li et al., 2015; McGlinchey and Aston-Jones, 2017). Differences between our results and the prior work on drug seeking also may be due to the fact that the latter animals had surgery for catheter placement, and performed bar-pressing tasks, or received daily injections, while our mice were free of handling and surgery and voluntarily left their home cage to seek MA.

\section{Novelty of our paradigm}

As has been previously documented, experimenteradministered drug treatments are useful in uncovering mechanisms underlying MA effects in the brain. However, these procedures do not allow the exploration of reinforcing effects of MA, nor do they parallel human drug-taking behaviors (Krasnova et al., 2016). Intravenous MA selfadministration protocols provide some face validity with respect to patterns of human MA intake, but retain the stresses associated with handling the animals and with the surgical procedures required for implants. A novel aspect of the present protocol is that the MA was available in a noninvasive voluntary intake protocol with animals living in their home cages. In these conditions, neural activation could be ascribed confidently to anticipatory responses, free from stresses associated with handling and surgery. Also, the MA was nebulized and inhaled by the mice; this is significant as intranasal administration represents the primary route of administration of MA for humans (Halkitis et al., 2003; Hart et al., 2008).

\section{Circadian effects}

The use of timed daily MA administration permitted incorporation of circadian analytic tools in our study. It is well established that the pharmacological, physiologic and behavioral responses to drugs are impacted by the time of administration (Levy, 1991; Ballesta et al., 2017; Prosser and Glass, 2017). By examining two different times of day, the present work contributes to our understanding CNS mechanisms associated with the anticipation of a psychostimulant and its modulation by diurnal rhythms. Our results agree with previous work showing 
that circadian modulation of drug-seeking behavior and other rewards peaks in the early morning hours (Webb et al., 2009; Baltazar et al., 2013; Webb et al., 2015). The results are also consistent with a substantial body of work that point to circadian and diurnal rhythms throughout the brain (Harbour et al., 2013; Silver and Kriegsfeld, 2014; Frederick et al., 2017). Three brain regions, the OB, LH, and DG, showed increased c-FOS expression with significant differences between early and late day for both MA and $W$ groups. We interpret these results to reveal the effects of MA on diurnal timing systems in these regions. Most neurons express circadian rhythms (Silver and Kriegsfeld, 2014) and thus it is not surprising to find that there are times of day effects in both MA and W groups. That said, highlighting endogenous diurnal responses, and how MA modulates them provides a tool for identifying drug effects.

Anticipatory activity to nebulized MA (but not W control) occurs not only in the voluntary access protocol, but is also seen when mice are placed daily by the experimenter into a chamber where MA was nebulized. Here too mice show more anticipatory activity in early versus late day (Keith et al., 2013). Similarly, they show more anticipatory activity in early day than in late day for free access to MA mixed with peanut butter (Keith et al., 2013). The preclinical evidence is consistent with clinical reports regarding drugs of abuse, in showing that admissions of overdose patients to the emergency department of urban hospitals are predominant in early evening, suggesting a diurnal effect (Raymond et al., 1992; Manfredini et al., 1994). In summary, behavioral studies consistently point to an important effect of time of day, in the absence of external cues, on the behaviors associated with many kinds of rewards, raising the question of the brain regions that are involved in anticipation.

\section{Endogenous circadian control}

Engagement of the endogenous circadian timing system is not under voluntary control, but the entrained responses of the brain and body develop over time, following repeated exposure (Fig. 2; Mistlberger, 1994). The evidence that circadian timing is involved is not simply that drugs administered at 24-h intervals produce circadian anticipatory activity that precedes daily drug availability by an hour or more, but also that anticipatory activity persists when the drug is withdrawn (Kosobud et al., 1998). The time of availability, at least in the case of food anticipation, is remembered for as long as two months following the initial exposure (Coleman et al., 1982; Yoshihara et al., 1997). The fact that anticipatory activity occurs even in SCN lesioned animals (lijima et al., 2002) points to the possibility that circadian timing information may derive not only from extra-SCN brain sites but also from bodily signals (Honma and Honma, 2009; Patton and Mistlberger, 2013). Taken together with the previous work, the present results point to the important effect of the circadian timing system in behavioral and neural aspects of anticipation of MA. The results also suggest that MA can alter the amplitude of rhythmic neural responses.

\section{References}

Acosta-Galvan G, Yi CX, van der Vliet J, Jhamandas JH, Panula P, Angeles-Castellanos M, Del Carmen Basualdo M, Escobar C, Buijs RM (2011) Interaction between hypothalamic dorsomedial nucleus and the suprachiasmatic nucleus determines intensity of food anticipatory behavior. Proc Natl Acad Sci USA 108:5813-5818.

Akiyama M, Yuasa T, Hayasaka N, Horikawa K, Sakurai T, Shibata S (2004) Reduced food anticipatory activity in genetically orexin (hypocretin) neuron-ablated mice. Eur J Neurosci 20:3054-3062.

Alonso-Alonso M, Woods SC, Pelchat M, Grigson PS, Stice E, Farooqi S, Khoo CS, Mattes RD, Beauchamp GK (2015) Food reward system: current perspectives and future research needs. Nutr Rev 73:296-307. CrossRef Medline

Angeles-Castellanos M, Aguilar-Roblero R, Escobar C (2004) c-Fos expression in hypothalamic nuclei of food-entrained rats. Am J Physiol 286:R158-R165.

Angeles-Castellanos M, Mendoza J, Escobar C (2007) Restricted feeding schedules phase shift daily rhythms of c-Fos and protein Per1 immunoreactivity in corticolimbic regions in rats. Neuroscience 144:344-355.

Ballesta A, Innominato PF, Dallmann R, Rand DA, Lévi FA (2017) Systems chronotherapeutics. Pharmacol Rev 69:161-199. CrossRef Medline

Baltazar RM, Coolen LM, Webb IC (2013) Diurnal rhythms in neural activation in the mesolimbic reward system: critical role of the medial prefrontal cortex. Eur J Neurosci 38:2319-2327.

Begriche K, Marston OJ, Rossi J, Burke LK, McDonald P, Heisler LK, Butler AA (2012) Melanocortin-3 receptors are involved in adaptation to restricted feeding. Genes Brain Behav 11:291-302.

Bellinger LL, Bernardis LL (2002) The dorsomedial hypothalamic nucleus and its role in ingestive behavior and body weight regulation: lessons learned from lesioning studies. Physiol Behav 76: 431-442. CrossRef

Berger B, Gaspar P, Verney C (1991) Dopaminergic innervation of the cerebral cortex: unexpected differences between rodents and primates. Trends Neurosci 14:21-27.

Blancas A, Gonzalez-Garcia SD, Rodriguez K, Escobar C (2014) Progressive anticipation in behavior and brain activation of rats exposed to scheduled daily palatable food. Neuroscience 281:4453.

Blum ID, Lamont EW, Rodrigues T, Abizaid A (2012) Isolating neural correlates of the pacemaker for food anticipation. PLoS One 7:e36117. CrossRef Medline

Butler MP, Silver R (2011) Divergent photic thresholds in the nonimage-forming visual system: entrainment, masking and pupillary light reflex. Proc Biol Sci 278:745-750.

Caba M, González-Mariscal G (2009) The rabbit pup, a natural model of nursing-anticipatory activity. Eur J Neurosci 30:1697-1706. CrossRef Medline

Caba M, Pabello M, Moreno ML, Meza E (2014) Main and accessory olfactory bulbs and their projections in the brain anticipate feeding in food-entrained rats. Chronobiol Int 31:869-877.

Calipari ES, Espana RA (2012) Hypocretin/orexin regulation of dopamine signaling: implications for reward and reinforcement mechanisms. Front Behav Neurosci 6:54.

Cetin T, Freudenberg F, Fuchtemeier M, Koch M (2004) Dopamine in the orbitofrontal cortex regulates operant responding under a progressive ratio of reinforcement in rats. Neurosci Lett 370:114117.

Challet E (2015) Keeping circadian time with hormones. Diabetes Obes Metab 17 [Suppl 1]:76-83. CrossRef Medline

Challet E, Jacob N, Vuillez P, Pévet P, Malan A (1997) Fos-like immunoreactivity in the circadian timing system of calorierestricted rats fed at dawn: daily rhythms and light pulse-induced changes. Brain Res 770:228-236. CrossRef

Childs E, de Wit $\mathrm{H}$ (2009) Amphetamine-induced place preference in humans. Biol Psychiatry 65:900-904. 
Childs E, de Wit H (2013) Contextual conditioning enhances the psychostimulant and incentive properties of d-amphetamine in humans. Addict Biol 18:985-992. CrossRef Medline

Coleman GJ, Harper S, Clarke JD, Armstrong S (1982) Evidence for a separate meal-associated oscillator in the rat. Physiol Behav 29:107-115. Medline

Cornish JL, Hunt GE, Robins L, McGregor IS (2012) Regional c-Fos and FosB/DeltaFosB expression associated with chronic methamphetamine self-administration and methamphetamine-seeking behavior in rats. Neuroscience 206:100-114

Dantas-Ferreira RF, Dumont S, Gourmelen S, Cipolla-Neto J, Simonneaux V, Pévet P, Challet E (2015) Food-anticipatory activity in Syrian hamsters: behavioral and molecular responses in the hypothalamus according to photoperiodic conditions. PLoS One 10:e0126519. CrossRef

Dattolo T, Coomans CP, van Diepen HC, Patton DF, Power S, Antle MC, Meijer JH, Mistlberger RE (2016) Neural activity in the suprachiasmatic circadian clock of nocturnal mice anticipating a daytime meal. Neuroscience 315:91-103.

Dunnett SB, Robbins TW (1992) The functional role of mesotelencephalic dopamine systems. Biol Rev Camb Philos Soc 67:491518.

Escobar C, Martinez-Merlos MT, Angeles-Castellanos M, del Carmen Minana M, Buijs RM (2007) Unpredictable feeding schedules unmask a system for daily resetting of behavioural and metabolic food entrainment. Eur J Neurosci 26:2804-2814.

Escobar C, Salgado R, Rodriguez K, Blancas Vazquez AS, AngelesCastellanos M, Buijs RM (2011) Scheduled meals and scheduled palatable snacks synchronize circadian rhythms: consequences for ingestive behavior. Physiol Behav 104:555-561.

Frederick A, Goldsmith J, de Zavalia N, Amir S (2017) Mapping the co-localization of the circadian proteins PER2 and BMAL1 with enkephalin and substance $P$ throughout the rodent forebrain. PLoS One 12:e0176279. CrossRef

Gallardo CM, Gunapala KM, King OD, Steele AD (2012) Daily scheduled high fat meals moderately entrain behavioral anticipatory activity, body temperature, and hypothalamic c-Fos activation. PLoS One 7:e41161.

Gallardo CM, Hsu CT, Gunapala KM, Parfyonov M, Chang $\mathrm{CH}$, Mistlberger RE, Steele AD (2014) Behavioral and neural correlates of acute and scheduled hunger in C57BL/6 mice. PLoS One 9:e95990.

Gooley JJ, Schomer A, Saper CB (2006) The dorsomedial hypothalamic nucleus is critical for the expression of food-entrainable circadian rhythms. Nat Neurosci 9:398-407.

Guillem K, Brenot V, Durand A, Ahmed SH (2017) Neuronal representation of individual heroin choices in the orbitofrontal cortex. Addict Biol. Advance online publication. July 13. doi: 10.1111/ adb.12536.

Halkitis PN, Parsons JT, Wilton L (2003) An exploratory study of contextual and situational factors related to methamphetamine use among gay and bisexual men in New York City. J Drug Issues 33:413-432.

Harbour VL, Weigl Y, Robinson B, Amir S (2013) Comprehensive mapping of regional expression of the clock protein PERIOD2 in rat forebrain across the 24-h day. PLoS One 8:e76391.

Hart CL, Gunderson EW, Perez A, Kirkpatrick MG, Thurmond A, Comer SD, Foltin RW (2008) Acute physiological and behavioral effects of intranasal methamphetamine in humans. Neuropsychopharmacology 33:1847-1855. CrossRef

Honma K, Honma S (2009) The SCN-independent clocks, methamphetamine and food restriction. Eur J Neurosci 30:1707-1717. CrossRef Medline

lijima M, Nikaido T, Akiyama M, Moriya T, Shibata S (2002) Methamphetamine-induced, suprachiasmatic nucleus-independent circadian rhythms of activity and mPer gene expression in the striatum of the mouse. Eur J Neurosci 16:921-929.

Izquierdo A (2017) Functional heterogeneity within rat orbitofrontal cortex in reward learning and decision making. J Neurosci 37: 10529-10540. CrossRef Medline
James MH, Mahler SV, Moorman DE, Aston-Jones G (2017) A decade of orexin/hypocretin and addiction: where are we now? Curr Top Behav Neurosci 33:247-281.

Juarez-Portilla C, Kim RD, Robotham M, Tariq M, Pitter M, LeSauter J, Silver R (2017) Voluntary inhalation of methamphetamine: a novel strategy for studying intake non-invasively. Psychopharmacology (Berl) 234:739-747.

Kahnt T, Tobler PN (2017) Dopamine modulates the functional organization of the orbitofrontal cortex. J Neurosci 37:1493-1504. CrossRef Medline

Keith DR, Hart CL, Robotham M, Tariq M, Le Sauter J, Silver R (2013) Time of day influences the voluntary intake and behavioral response to methamphetamine and food reward. Pharmacol Biochem Behav 110:117-126.

Kosobud AE, Pecoraro NC, Rebec GV, Timberlake W (1998) Circadian activity precedes daily methamphetamine injections in the rat. Neurosci Lett 250:99-102.

Krasnova IN, Justinova Z, Cadet JL (2016) Methamphetamine addiction: involvement of CREB and neuroinflammatory signaling pathways. Psychopharmacology (Berl) 233:1945-1962. CrossRef

Landry GJ, Simon MM, Webb IC, Mistlberger RE (2006) Persistence of a behavioral food-anticipatory circadian rhythm following dorsomedial hypothalamic ablation in rats. Am J Physiol 290:R1527R1534.

Landry GJ, Yamakawa GR, Webb IC, Mear RJ, Mistlberger RE (2007) The dorsomedial hypothalamic nucleus is not necessary for the expression of circadian food-anticipatory activity in rats. J Biol Rhythms 22:467-478

Le Merrer J, Gavello-Baudy S, Galey D, Cazala P (2007) Morphine self-administration into the lateral septum depends on dopaminergic mechanisms: evidence from pharmacology and Fos neuroimaging. Behav Rrain Res 180:203-217.

LeSauter J, Hoque N, Weintraub M, Pfaff DW, Silver R (2009) Stomach ghrelin-secreting cells as food-entrainable circadian clocks. Proc Natl Acad Sci USA 106:13582-13587.

Levy G (1991) Chronotherapeutics. Pharmacokinetic constraints and opportunities. Ann NY Acad Sci 618:116-122. Medline

Li X, Rubio FJ, Zeric T, Bossert JM, Kambhampati S, Cates HM, Kennedy PJ, Liu QR, Cimbro R, Hope BT, Nestler EJ, Shaham Y (2015) Incubation of methamphetamine craving is associated with selective increases in expression of Bdnf and trkb, glutamate receptors, and epigenetic enzymes in cue-activated fos-expressing dorsal striatal neurons. J Neurosci 35:8232-8244. CrossRef

Luna-Illades C, Morales T, Miranda-Anaya M (2017) Decreased food anticipatory activity of obese mice relates to hypothalamic c-Fos expression. Physiol Behav 179:9-15. CrossRef Medline

Luo AH, Tahsili-Fahadan P, Wise RA, Lupica CR, Aston-Jones G (2011) Linking context with reward: a functional circuit from hippocampal CA3 to ventral tegmental area. Science 333:353-357. CrossRef

Manfredini R, Gallerani M, Calo G, Pasin M, Govoni M, Fersini C (1994) Emergency admissions of opioid drug abusers for overdose: a chronobiological study of enhanced risk. Ann Emerg Med 24:615-618. Medline

Mayo LM, Fraser D, Childs E, Momenan R, Hommer DW, de Wit $\mathrm{H}$, Heilig M (2013) Conditioned preference to a methamphetamineassociated contextual cue in humans. Neuropsychopharmacology 38:921-929.

McGlinchey EM, Aston-Jones G (2017) Dorsal hippocampus drives context-induced cocaine seeking via inputs to lateral septum. Neuropsychopharmacology 43:987-1000.

Mellers B, Schwartz A, Ritov I (1999) Emotion-based choice. J Exp Psychol Gen 128:332-345.

Mendoza J, Angeles-Castellanos M, Escobar C (2005) Entrainment by a palatable meal induces food-anticipatory activity and c-Fos expression in reward-related areas of the brain. Neuroscience 133:293-303. CrossRef

Mistlberger RE (1994) Circadian food-anticipatory activity: formal models and physiological mechanisms. Neurosci Biobehav Rev 18:171-195. CrossRef 
Mistlberger RE, Kent BA, Chan S, Patton DF, Weinberg A, Parfyonov M (2012) Circadian clocks for all meal-times: anticipation of 2 daily meals in rats. PLoS One 7:e31772. CrossRef

Mitra A, Lenglos C, Martin J, Mbende N, Gagne A, Timofeeva E (2011) Sucrose modifies c-fos mRNA expression in the brain of rats maintained on feeding schedules. Neuroscience 192:459474.

Mrosovsky N, Hattar S (2003) Impaired masking responses to light in melanopsin-knockout mice. Chronobiol Int 20:989-999. Medline

Neisewander JL, Baker DA, Fuchs RA, Tran-Nguyen LT, Palmer A, Marshall JF (2000) Fos protein expression and cocaine-seeking behavior in rats after exposure to a cocaine self-administration environment. J Neurosci 20:798-805.

O'Doherty J, Rolls ET, Francis S, Bowtell R, McGlone F, Kobal G, Renner B, Ahne G (2000) Sensory-specific satiety-related olfactory activation of the human orbitofrontal cortex. Neuroreport 11:893897.

Olds J, Milner P (1954) Positive reinforcement produced by electrical stimulation of septal area and other regions of rat brain. J Comp Physiol Psychol 47:419-427.

Ott V, Friedrich M, Prilop S, Lehnert H, Jauch-Chara K, Born J, Hallschmid M (2011) Food anticipation and subsequent food withdrawal increase serum cortisol in healthy men. Physiol Behav 103:594-599. CrossRef Medline

Ott V, Friedrich M, Zemlin J, Lehnert H, Schultes B, Born J, Hallschmid M (2012) Meal anticipation potentiates postprandial ghrelin suppression in humans. Psychoneuroendocrinology 37 : 1096-1100.

Patton DF, Mistlberger RE (2013) Circadian adaptations to meal timing: neuroendocrine mechanisms. Front Neurosci 7:185.

Patton DF, Parfyonov M, Gourmelen S, Opiol H, Pavlovski I, Marchant EG, Challet E, Mistlberger RE (2013) Photic and pineal modulation of food anticipatory circadian activity rhythms in rodents. PLoS One 8:e81588. CrossRef Medline

Patton DF, Katsuyama AM, Pavlovski I, Michalik M, Patterson Z, Parfyonov M, Smit AN, Marchant EG, Chung SH, Abizaid A, Storch KF, de la Iglesia H, Mistlberger RE (2014) Circadian mechanisms of food anticipatory rhythms in rats fed once or twice daily: clock gene and endocrine correlates. PLoS One 9:e112451. CrossRef Medline

Paxinos G, Franklin K (2013) Paxinos and Franklin's the mouse brain in stereotaxic coordinates. New York: Elsevier.

Pitchers KK, Vialou V, Nestler EJ, Laviolette SR, Lehman MN, Coolen LM (2013) Natural and drug rewards act on common neural plasticity mechanisms with DeltaFosB as a key mediator. J Neurosci 33:3434-3442.

Pittendrigh CS (1981) Circadian systems: entrainment. In: Biological rhythms (Aschoff J, ed), pp 94-124. New York: Springer US.

Pittendrigh CS, Minis DH (1964) The entrainment of circadian oscillations by light and their role as photoperiodic clocks. Am Nat 98:261-294.

Poulin AM, Timofeeva E (2008) The dynamics of neuronal activation during food anticipation and feeding in the brain of food-entrained rats. Brain Res 1227:128-141. CrossRef Medline

Prosser RA, Glass JD (2017) Neurological aspects of cocaine and the suprachiasmatic circadian clock. In: The neuroscience of cocaine: mechanisms and treatment (Preedy VR, ed), pp 163-172. London: Academic Press.

Randt CT, Quartermain D (1972) Motivation for electrical stimulation of the brain and for natural reinforcement in mice. Exp Neurol 35:366-377.

Raymond RC, Warren M, Morris RW, Leikin JB (1992) Periodicity of presentations of drugs of abuse and overdose in an emergency department. J Toxicol Clin Toxicol 30:467-478.

Rhodes JS, Ryabinin AE, Crabbe JC (2005) Patterns of brain activation associated with contextual conditioning to methamphetamine in mice. Behav Neurosci 119:759-771.
Richards JR, Laurin EG (2018) Toxicity, methamphetamine. Treasure Island: StatPearls. StatPearls Publishing LLC. Treasure Island, FL.

Rolls ET (2000) The orbitofrontal cortex and reward. Cereb Cortex 10:284-294. Medline

Rosenwasser AM, Fixaris MC, McCulley WD 3rd (2015) Photoperiodic modulation of voluntary ethanol intake in C57BL/6 mice. Physiol Behav 147:342-347. CrossRef

Ruby NF, Fisher N, Patton DF, Paul MJ, Fernandez F, Heller HC (2017) Scheduled feeding restores memory and modulates c-Fos expression in the suprachiasmatic nucleus and septohippocampal complex. Sci Rep 7:6755

Schindelin J, Arganda-Carreras I, Frise E, Kaynig V, Longair M, Pietzsch T, Preibisch S, Rueden C, Saalfeld S, Schmid B, Tinevez JY, White DJ, Hartenstein V, Eliceiri K, Tomancak P, Cardona A (2012) Fiji: an open-source platform for biological-image analysis. Nat Methods 9:676-682.

Schoenbaum G, Shaham Y (2008) The role of orbitofrontal cortex in drug addiction: a review of preclinical studies. Biol Psychiatry 63:256-262. CrossRef Medline

Sheehan TP, Chambers RA, Russell DS (2004) Regulation of affect by the lateral septum: implications for neuropsychiatry. Brain Res Brain Res Rev 46:71-117.

Shibata S, Minamoto Y, Ono M, Watanabe S (1994) Aging impairs methamphetamine-induced free-running and anticipatory locomotor activity rhythms in rats. Neurosci Lett 172:107-110.

Siegel S (2005) Drug tolerance, drug addiction, and drug anticipation. Curr Dir Psychol Sci 14:296-300. CrossRef

Siegel S, Ramos BM (2002) Applying laboratory research: drug anticipation and the treatment of drug addiction. Exp Clin Psychopharmacol 10:162-183. Medline

Silver R, Kriegsfeld LJ (2014) Circadian rhythms have broad implications for understanding brain and behavior. Eur $\mathrm{J}$ Neurosci 39:1866-1880. CrossRef Medline

Stephan FK (1983) Circadian rhythm dissociation induced by periodic feeding in rats with suprachiasmatic lesions. Behav Brain Res 7:81-98. CrossRef

Stewart JL, May AC, Tapert SF, Paulus MP (2015) Hyperactivation to pleasant interoceptive stimuli characterizes the transition to stimulant addiction. Drug Alcohol Depend 154:264-270.

Strubbe JH, Woods SC (2004) The timing of meals. Psychol Rev 111:128-141. CrossRef Medline

Tataroglu O, Davidson AJ, Benvenuto LJ, Menaker M (2006) The methamphetamine-sensitive circadian oscillator (MASCO) in mice. J Biol Rhythms 21:185-194.

Tomasi D, Wang GJ, Wang R, Caparelli EC, Logan J, Volkow ND (2015) Overlapping patterns of brain activation to food and cocaine cues in cocaine abusers: association to striatal D2/D3 receptors. Hum Brain Mapp 36:120-136. CrossRef

United-Nations (2011) United Nations Office on Drugs and Crime: world drug report 2011. Available at http://www.unodc.org/ documents/data-and-analysis/WDR2011/WDR2011-ExSum.pdf.

Volkow ND, Fowler JS (2000) Addiction, a disease of compulsion and drive: involvement of the orbitofrontal cortex. Cereb Cortex 10: 318-325. Medline

Webb IC, Baltazar RM, Lehman MN, Coolen LM (2009) Bidirectional interactions between the circadian and reward systems: is restricted food access a unique zeitgeber? Eur J Neurosci 30:17391748.

Webb IC, Lehman MN, Coolen LM (2015) Diurnal and circadian regulation of reward-related neurophysiology and behavior. Physiol Behav 143:58-69.

Yates JR, Darna M, Beckmann JS, Dwoskin LP, Bardo MT (2016) Individual differences in impulsive action and dopamine transporter function in rat orbitofrontal cortex. Neuroscience 313:122129

Yoshihara T, Honma S, Mitome M, Honma K (1997) Independence of feeding-associated circadian rhythm from light conditions and meal intervals in SCN lesioned rats. Neurosci Lett 222:95-98. 